\title{
Factors determining sleep in patients hospitalised in ICUs in a hospital in Northern Poland
}

\author{
Katarzyna Lewandowska ${ }^{1} \cdot$ Wioletta Mędrzycka-Dąbrowska ${ }^{1}$ (D) Katarzyna Kwiecień-Jaguś ${ }^{1}$. \\ Katarzyna Czyż-Szypenbejl ${ }^{1}$
}

Received: 23 August 2018 / Accepted: 1 January 2019 / Published online: 8 February 2019

(c) The Author(s) 2019

\begin{abstract}
Evaluation of sleep quality and sleep-disturbing factors in patients in an Intensive Care Unit (ICU). Over 8 months, 83 persons were examined as part of the recruitment of patients hospitalised in the ICU. The interviewer conducted interviews with the patients on the third day following their discharge from the ICU. Patients had to successfully complete the Short Portable Mental Status Questionnaire. The patients whose results reflected their normal mental status were administered the Richards-Campbell Sleep Questionnaire to evaluate the quality of sleep. A modified Freedman questionnaire was then administered. It was discovered that factors which disturb sleep most include the measurement of vital signs (3.28/10) and light (3.18/10) $(1=$ no disturbance, $10=$ significant disturbance). It was also determined that the higher the VAS reported during the first day in the ICU, the higher the importance of pain in sleep disturbance in the ICU, $Z=-2.65 ; p<0.05$. The study results indicate that sleep disturbance in an ICU results from many factors. A comprehensive approach to a patient's night rest is required. A reduction of sleep-disturbing factors could result in an improvement of the quality of sleep in an ICU. What remains to be done is to turn the attention of the medical staff working in an ICU to the importance of sleep and raise their awareness of the factors which may affect it.
\end{abstract}

Keywords Sleep disturbance $\cdot$ Intensive treatment unit $\cdot$ Sleep $\cdot$ ICU $\cdot$ Determinants

\section{Introduction}

In its complexity, the Intensive Care Unit (ICU) environment is largely based on the continuous observation and monitoring of the patient. As a result, the physical and technical aspects of care are given priority, while the mental sphere and the patient's needs are largely omitted [1]. These needs include sleep, which, in the light of advanced medical procedures performed in an ICU, may seem to be less significant. Sleep is indispensable for regeneration and physiological rest. Sleep shortages may cause an increased risk of infection, endocrine disruption, decreased glucose tolerance, and increased sympathetic activity [2]. It is also worth looking at the problem of sleep deficit and lowered quality of sleep in the context of the patient's disturbed sense of safety. In

Wioletta Mędrzycka-Dąbrowska

wioletta.medrzycka@gumed.edu.pl

1 Department of Anaesthesiology Nursing and Intensive Care, Medical University in Gdansk, Ul. Dębinki 7, 80-952 Gdańsk, Poland
2013, researchers from Australia conducted retrospective interviews with patients hospitalised in ICUs. The subjects could not sleep, because another patient staying in the same department had died, and they felt insecure. They were too frightened to sleep in a place in which death was common. As one of the subjects put it: "I could not sleep because people were dying around me". The patient stayed awake, since it made him feel safe [3].

During hospitalisation in an ICU, the structure of sleep changes, with light sleep taking up as much as $90 \%$ of the total sleep time (TST) (NREM stages 1 and 2 dominate). For most of its duration, sleep is devoid of its deep and regenerating stage (decrease in NREM stage 3 and REM) [4]. Research carried out in 2008 showed that within $24 \mathrm{~h}$, ICU patients experienced $41 \pm 28$ sleep episodes lasting no longer than $15 \pm 9 \mathrm{~min}$. Therefore, sleep was marked by high fragmentation and low effectiveness [5]. Apart from physiological changes in sleep structure, sleep quality is also affected. More than $60 \%$ of ICU patients reported sleep disturbances or a total lack of sleep during hospitalisation $[6,7]$. Other studies showed that patients recalled frequent sleep interruptions as well as pain, anxiety, 
and fear, which affected their ability to sleep [7, 8]. A study carried out on 464 patients reported that $51 \%$ of the subjects experienced dreams and nightmares and that $14 \%$ of them additionally declared that 6 months after their stay in the ICU, nightmares had a negative impact on the quality of their lives [9].

An analysis of the structure of sleep of unconscious ICU patients is possible owing to advanced monitoring of the electrical activity of the brain and sleep parameters. When it is possible to establish contact with an ICU patient, ready assessment scales can be used. There are objective and subjective methods of assessment. The objective ones include complete polysomnography (as a gold standard), the bispectral index (BIS), and actigraphy. The subjective ones include the patient's own evaluation of sleep and sleep assessment performed by medical staff with the help of standardised tools $[10,11]$. The subjective methods make it possible to assess the sleep of a larger number of ICU patients [12].

There are many factors responsible for the sleep disturbances of ICU patients. The specific environment with invasive treatment contributes to such disturbances. The patients' individual illnesses, their earlier experience, and the changing severity of disease are also responsible for the absence of physiological sleep. There is no doubt that reasons behind sleep disturbances in an ICU include the environment of the department, constant noise made by the alarms of monitors and medical ventilators, light, and a considerable number of medical procedures both at night and during the day. Clinical observations carried out so far show that patients with diagnosed circulatory failure and chronic obstructive pulmonary disease have sleep problems connected with night apnea. Postoperative surgical patients in an ICU experience difficulties with falling asleep and sleeping due to pain and the related anxiety [13, 14]. Sleep disturbances are also very frequent in patients suffering from respiratory failure treated with a ventilator [8]. Pharmacotherapy is yet another equally important factor affecting the particular sleep stages. On one hand, it is an indispensable element of treatment, which often saves ICU patients' lives and minimizes their pain, but on the other hand, it may seriously affect sleep and even cause insomnia incidents [15].

\section{Aim}

The aim of the work was evaluation of sleep quality and sleepdisturbing factors in patients in ICU.

\section{Methods}

\section{Design}

The study reconnaissance descriptive and qualitative content analysis was used to present the evaluation of sleep quality and sleep-disturbing factors in patients in an intensive care unit.

\section{Study procedures}

The research was carried out at the University Clinical Centre in Gdańsk in 2017 and 2018. Over 8 months, 83 persons were examined as part of the recruitment of patients hospitalised in the ICU. The interviewer conducted interviews with the patients on the third day following their discharge from the ICU, when they were still in hospital. Demographic data were collected prior to the interviews for about $15 \mathrm{~min}$. The data concerned sex, age, length of stay in the ICU, reasons behind the hospitalisation, the duration of ventilation therapy, the administered pharmaceuticals, and VAS for pain. The interviews themselves, including the filling-in of forms, lasted for 15-25 min. The interviewer asked the patients questions and recorded their answers.

\section{Inclusion and exclusion criteria}

The study was performed on ICU patients who expressed their consent to participate. The patients who did not express their consent or scored more than five points in the Short Portable Mental Status Questionnaire were excluded from participation [16].

\section{Questionnaire development}

The questionnaires used included the Richards-Campbell Sleep Questionnaire (RCSQ) [17] composed of five elements assessed by the patient: depth of sleep, duration of falling asleep, duration of sleep, time between waking up and falling asleep, and general sleep evaluation. The patients assessed their sleep on a $0-10$ scale. The questionnaire concerned the previous night, that is, spent in the mother ward after the hospitalisation at the ICU. The second questionnaire used was a modified Freedman scale developed by Shailesh Bihari (Fig. 1) [1]. The questionnaire required retrospection, and the subjects were asked to evaluate their general sleep quality on a 10-point scale, where 1 stood for the worst possible quality and 10 for the best possible quality. The evaluation applied sleep in the ICU. The subjects were also asked to assess their sleepiness during the day $(1=$ inability to stay awake, $10=$ full alertness). They then evaluated, 


\begin{tabular}{|c|c|c|c|c|c|}
\hline $\begin{array}{c}\text { Rate the overall quality } \\
\text { of your sleep at home } \\
\text { ( } 1 \text { is poor and } 10 \text { is } \\
\text { excellent) }\end{array}$ & 123456678910 & \multicolumn{4}{|c|}{$\begin{array}{l}\text { Rate how disruptive the following activities were to your sleep during your ICU stay } \\
\text { ( } 1 \text { is no disruption ; } 10 \text { is significant disruption) }\end{array}$} \\
\hline $\begin{array}{l}\text { Rate the overall quality of } \\
\text { your sleep in the ICU } \\
\text { ( } 1 \text { is poor and } 10 \text { is } \\
\text { excellent) }\end{array}$ & 1234456788910 & Pain & 123456678910 & $\begin{array}{l}\text { Heart monitor } \\
\text { alarm }\end{array}$ & 123456788910 \\
\hline $\begin{array}{l}\text { Rate the overall quality of } \\
\text { your sleep in the ICU on } \\
\text { the following nights }\end{array}$ & \multirow{3}{*}{ 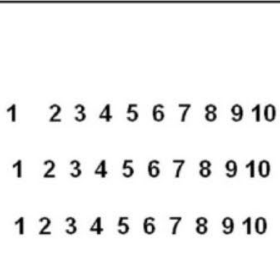 } & Noise & $\begin{array}{llllllllll}1 & 2 & 3 & 4 & 5 & 6 & 7 & 8 & 9 & 10\end{array}$ & Ventilator alarm & 12345678910 \\
\hline On first night of ICU & & Light & 1233456788910 & $\begin{array}{l}\text { Oxygen finger } \\
\text { probe }\end{array}$ & 123456788910 \\
\hline $\begin{array}{l}\text { During middle of ICU stay } \\
\text { End of your ICU stay }\end{array}$ & & $\begin{array}{l}\text { Nursing } \\
\text { interventions }\end{array}$ & 123456788910 & Talking & 123456678910 \\
\hline $\begin{array}{l}\text { 4. Rate the overall degree } \\
\text { of daytime sleepiness } \\
\text { during your ICU stay } \\
\text { ( } 1 \text { is unable to stay awake } \\
; 10 \text { is fully alert and } \\
\text { awake) }\end{array}$ & 12234556788910 & $\begin{array}{l}\text { Diagnostic } \\
\text { testing }\end{array}$ & 12345678910 & $\begin{array}{l}\text { Intra venous pump } \\
\text { alarm }\end{array}$ & 12345678910 \\
\hline $\begin{array}{l}\text { Rate the overall degree of } \\
\text { daytime sleepiness during } \\
\text { your ICU stay on the } \\
\text { following days }\end{array}$ & \multirow{4}{*}{ 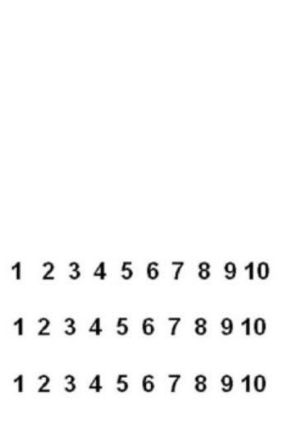 } & $\begin{array}{l}\text { Vitals signs } \\
\text { measurement }\end{array}$ & 12345678910 & Nebulizer & 123456788910 \\
\hline $\begin{array}{l}\text { On first day of ICU } \\
\text { (after extubation from } \\
\text { endo tracheal intubation) }\end{array}$ & & Blood samples & 1233456788910 & $\begin{array}{l}\text { Doctors/ nurses } \\
\text { pagers and phones }\end{array}$ & 12345678910 \\
\hline $\begin{array}{l}\text { During the middle of your } \\
\text { ICU stay }\end{array}$ & & \multirow{2}{*}{$\begin{array}{l}\text { Administration } \\
\text { of medicines }\end{array}$} & \multirow[b]{2}{*}{12345678910} & Television & 12345678910 \\
\hline $\begin{array}{l}\text { At the end of your ICU } \\
\text { stay }\end{array}$ & & & & Bedside phone & 12345678910 \\
\hline
\end{tabular}

*10-point modified Freedman scale (1 = no disturbance, 10 = significant disturbance).

Fig. 1 Sleep questionnaire a modified Freedman scale (asterisk) developed by Shailesh Bihari [13]

using a 10-point scale, the extent to which various environmental factors disturbed their sleep in the ICU $(1=$ no disturbance, $10=$ significant disturbance). Mental status was assessed with the help of the Short Portable Mental Status Questionnaire. Orientation, memory, social adjustment, and logical thinking skills were evaluated. Written consent to use the research tools was obtained from their authors.

\section{ICU environment}

Conditions in the ICU under study are highly standardised, with a 1:2 nursing staff to patient ratio. Each patient station is equipped with full monitoring of vital signs and the highest quality beds to improve the patients' comfort. The architecture of the facility has an open structure. The rooms are spacious, there is ample space between beds, and there are screens for the privacy and intimacy of the patients. Technical conditions are consistent with Polish legislation and ICU standards (The ordinance of the Minister of Health of 16
December 2016 on organisational standards of healthcare in the area of anaesthesiology and intensive care. Accessed July 20th, 2018) [18]. It is possible to maintain natural light. Between 8:00 a.m. and 10:00 a.m., patients undergo hygiene procedures, while pressure ulcer prevention takes place regularly on a 24-h basis. Vital signs are documented every hour/ $2 \mathrm{~h}$, depending on the patient's condition; monitoring is constant. Each patient undergoes physiotherapy with a physiotherapist.

\section{Statistical analysis}

All statistics were calculated with the help of the IBM SPSS 23 statistical package and the Excel 2013 spreadsheet. Qualitative variables were presented in numbers and percentages, and quantitative variables were expressed as the arithmetic mean and standard deviation. The Kolmogorov-Smirnov test was used for checking whether the quantitative variable originated from a population with normal distribution. The 
significance of differences between more than two groups was checked using the non-parametric Kruskal-Wallis test, and the significance of differences between two groups was tested with Student's $t$ distribution and the Mann-Whitney $U$ test. The Spearman's rank correlation test was used for checking the correlation between strength and direction. The statistical significance of $p<0.05$ was adopted in all the tests.

\section{Results}

The study was carried out on 93 patients. Nine of them were excluded due to lack of consent, and they all successfully completed the Short Portable Mental Status Questionnaire, with one questionnaire empty. 83 sets of questionnaires were finally obtained.

The subjects included 30 women and 53 men. Their ages ranged from 19 to 91 years $(S D \pm 16.46)$. The main reason for their stay in the ICU was extensive surgery requiring intensive surveillance (98.8\%). They stayed in the ICU for $1-10$ days $(S D \pm 1.42)$. Ventilator therapy lasted from $1 \mathrm{~h}$ to $96 \mathrm{~h}(\mathrm{SD} \pm 13.80) .50 .6 \%$ of patients declared some sleep disturbances prior to hospitalisation (Table 1).

\section{Quality of sleep in the ICU}

The general quality of the patients' sleep was assessed on the basis of a modified Freedman questionnaire. Four variables were combined, including the general quality of sleep, the quality of sleep during the first and the last days of the patients' stay in the ICU, and the quality of their sleep in the middle of the stay. It was impossible to generate data for the particular stages due to the patients' difficulties in locating particular days of their hospitalisation. As a result of the combination of variables, researchers had to adjust the scores related to sleep quality. After the variables were combined, scores ranged from 0 to 40 , with a score of $0-13$ equivalent to low quality of sleep, 14-26 to average quality of sleep, and 27-40 to high quality of sleep. The score for the ICU was (mean $=17.61 ; \mathrm{SD}=8.99$ ), and therefore, we may say that the patients evaluated the quality of their sleep as average (Table 2).

Table 2 Evaluation of the overall quality of sleep in ICU

\begin{tabular}{llllll}
\hline & $N$ & $\operatorname{Min}$ & $\operatorname{Max}$ & $M$ & $\mathrm{SD}$ \\
\hline $\begin{array}{l}\text { Evaluation of the overall quality of } \\
\text { sleep in ICU }\end{array}$ & 83 & 5 & 40 & 17.61 & 8.99 \\
\hline
\end{tabular}

Table 1 Patient demographics

\begin{tabular}{|c|c|c|c|c|c|c|}
\hline Data & $N$ & $\%$ & Min & $\operatorname{Max}$ & $M$ & SD \\
\hline \multicolumn{7}{|l|}{ Płeć } \\
\hline Women & 30 & 36.1 & - & - & - & - \\
\hline Men & 53 & 63.1 & - & - & - & - \\
\hline \multicolumn{7}{|l|}{ Age } \\
\hline- & 83 & - & 18 & 91 & 91.01 & 16.46 \\
\hline \multicolumn{7}{|c|}{ The number of days spent on the ICU } \\
\hline- & 83 & - & 1 & 10 & 1.58 & 1.42 \\
\hline \multicolumn{7}{|c|}{ The reason for hospitalisation } \\
\hline Circulatory failure & 4 & 4.82 & - & - & - & - \\
\hline Extensive surgery & 79 & 95.18 & - & - & - & - \\
\hline \multicolumn{7}{|c|}{ The duration of ventilation therapy in hours } \\
\hline- & 72 & - & 1 & 96 & 8.81 & 13.80 \\
\hline \multicolumn{7}{|c|}{ Medicines administered during the stay at ICU } \\
\hline Benzodiazepines & 17 & 7.5 & - & - & - & - \\
\hline Opioids & 80 & 35.4 & - & - & - & - \\
\hline Groups SSRI drugs & 1 & 0.4 & - & - & - & - \\
\hline Catecholamine & 17 & 7.5 & - & - & - & - \\
\hline Sleep medications & 14 & 6.2 & - & - & - & - \\
\hline Magnesium & 6 & 2.7 & - & - & - & - \\
\hline Beta-blockers & 2 & 0.9 & - & - & - & - \\
\hline Diuretics & 73 & 32.3 & - & - & - & - \\
\hline Steroids & 16 & 7.1 & - & - & - & - \\
\hline \multicolumn{7}{|c|}{ Pain in the first days of ICU stay } \\
\hline- & 75 & - & 0 & 6 & 2.36 & 1.50 \\
\hline
\end{tabular}


Table 3 Relationship between sleep disorders before hospitalisation and the quality of sleep in ICU

\begin{tabular}{lllllll}
\hline $\begin{array}{l}\text { The quality of sleep ICU vs sleep } \\
\text { disorders before hospitalisation }\end{array}$ & $N$ & $M$ & SD & $t$ & $d f$ & $p$ \\
\hline Yes-there were disorders & 42 & 18.28 & 9.03 & 0.69 & 81 & 0.495 \\
They did not enter the disorderia & 41 & 16.92 & 9.00 & 0.69 & 81 & 0.495 \\
\hline
\end{tabular}

Table 4 Sleep assessment of patients in parent branch using RCSQ

\begin{tabular}{|c|c|c|c|c|c|}
\hline Richard Campbell Sleep Questionnaire & $N$ & Min & Max & $M$ & SD \\
\hline Last night I slept (deep—0/slightly-10) & 83 & 0 & 10 & 4.82 & 2.70 \\
\hline $\begin{array}{l}\text { Last night. when I went to sleep for the first time (I fell asleep almost } \\
\text { immediately-0/I could not sleep at all-10) }\end{array}$ & 83 & 0 & 9 & 4.39 & 2.29 \\
\hline Last night (I slept almost all the time $-0 / \mathrm{I}$ did not sleep at all -10 ) & 83 & 0 & 10 & 4.53 & 2.17 \\
\hline $\begin{array}{l}\text { Last night when I was up or was awake (immediately fell asleep } \\
\text { again—0/I could not sleep anymore-10) }\end{array}$ & 83 & 0 & 10 & 4.53 & 2.24 \\
\hline Last night I slept (well-0/bad-10) & 83 & 0 & 10 & 4.65 & 2.30 \\
\hline
\end{tabular}

It was also found that sleep disturbances prior to hospitalisation did not affect the quality of sleep in the ICU. To verify the hypothesis, the Student's $t$ test for independent samples was used. No statistically significant relationships between variables were obtained: $t_{(81)}=0.69 ; p>0.05$ (Table 3).

We noticed that along with an increase in the general quality of sleep in the ICU, the quality of sleep during the subsequent days of stay in the ICU increased as well. A number of Spearman's rank correlation tests were applied and the analysis showed that along with an increase in the general sleep quality in the ICU, there was an increase in the quality of sleep on the first night of the stay $\rho=0.88$; $p<0.001$, in the middle of the stay $\rho=0.93 ; p<0.001$ and on the last night of the stay $\rho=0.93 ; p<0.001$.

\section{Sleep at the primary department following hospitalisation in the ICU}

No relationship was discovered between the ability to fall asleep fast at the PD, and the strong feeling of sleepiness during the patients' stay in the ICU. It may seem that strong sleepiness in the ICU may have a positive impact on how fast patients fall asleep, but after the Spearman's rank correlation test was applied, the analysis did not show any correlation between the variables $\rho=-0.06 ; p>0.05$.

The patients described their sleep at the PD on the basis of the RCSQ - the results do not show an extreme assessment of sleep. After averaging, the majority of answers ranged between 4.39 and $4.86 \mathrm{M}$ (Table 4 ).

\section{Factors disturbing sleep in the ICU}

The Freedman questionnaire clearly shows the distribution of factors disturbing sleep during the patients' stay in

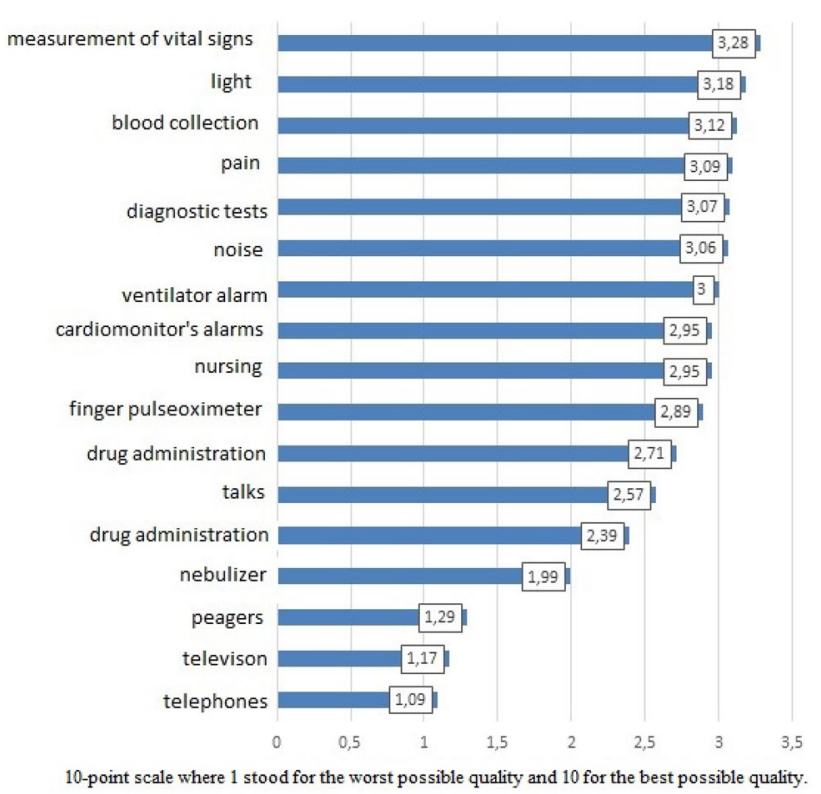

Fig. 2 Environmental factors interfering with sleep in ICU

the ICU. The factor which disturbed sleep most was the measurement of vital signs, which scored 3.28 points (on a 10-point scale), and phones by the patients' beds were identified as the least disturbing factor, scoring 1.09 points (on a 10-point scale). A detailed distribution of reasons behind sleep disturbances is shown in Fig. 2 .

Pain as a factor disturbing sleep in an ICU ranked fourth, and it was additionally determined that the higher the level of pain reported on the first day of hospitalisation in the ICU, the stronger the position of pain as a sleepdisturbing factor. The Spearman's rank correlation test was used: $\rho=0.31 ; p<0.05$. 
We also attempted to find a relationship between the feeling of sleepiness in an ICU and the administration of opioids, but since the group taking opioid analgesics was too large, it became impossible. Only three patients did not receive any opioids during hospitalisation. Surprisingly, the group of patients taking catecholamines assessed their sleep quality as better. To verify the hypothesis, the nonparametric Mann-Whitney $U$ test of significance was used. Statistically significant correlations were obtained for the variables with $Z=-2.65 ; p<0.05$ (Table 5 ). The analysis showed statistically significantly that the quality of sleep in ICU patients who were administered catecholamines was better than that experienced by patients who were not given the compounds.

No relationship was identified between the duration of ventilator therapy and the ventilator alarm as a sleep-disturbing factor. The Spearman's rank correlation test was applied: $\rho=-0.11 ; p>0.05$.

\section{Discussion}

As everyone knows, sleep plays a significant role in the functioning of every human being. Sleep disorders have their serious health consequences and can have a significant impact on the body's immune system, circulatory system, and cognitive functions. Numerous scientific reports indicate that sleep disorders are a very important problem for patients hospitalised in the ICU. The above studies are the first studies in Poland addressing sleep disorders. We met with a lack of understanding on the part of personnel working on the subject of research and lack of cooperation. However, we have managed to prove that the sleep quality of patients hospitalised in the ICU is average. It also turned out that sleep disorders occurring before hospitalisation do not affect the quality of sleep in ICU. It was noticed that with the increase in the overall quality of sleep in ICU, the quality of sleep increased in the next days of ICU stay. The factor that most disturbed sleep was the measurement of vital signs, which reached 3.38/10. In addition, the results of this study show that pain is still a problem in Polish hospitals-it is the fourth on the list of sleep disruptors. It has been shown that the higher the level of pain reported in the first day of ICU hospitalisation, the stronger the position of pain as a factor affecting sleep.

Table 5 Sleep quality of patients receiving catecholamines

\begin{tabular}{llllll}
\hline $\begin{array}{l}\text { The quality of sleep in } \\
\text { ICU vs catecholamines }\end{array}$ & $N$ & $M$ & $S D$ & $Z$ & $p$ \\
\hline No & 66 & 16.15 & 8.24 & 2.65 & $\mathbf{0 . 0 0 8}$ \\
Yes & 17 & 23.29 & 9.75 & 2.65 & $\mathbf{0 . 0 0 8}$ \\
\hline
\end{tabular}

The evaluation of sleep with the help of questionnaires is a subjective method which allows the testing of a larger population of patients. However, it is polysomnography, as the gold standard, which allows an objective look at concrete sleep stages and their evaluation during night rest. In this study, patients assessed the quality of their sleep during their stay in the ICU as average. After using polysomnography, Freedman-the author of the original questionnaire used in this study, noticed a shortening of the total duration of night rest, which during a 24-test lasted for $8.8 \pm 5 \mathrm{~h}$ and was marked by many awakenings during the day (57) and at night (43) [6]. This shows how much sleep in an ICU differs from physiological sleep and to what extent it is disturbed. Research carried out with the help of the modified Freedman questionnaire showed that the quality of sleep ranged between $4.0 \pm 1.7,(p>0.001)$ on a 10-point scale. Therefore, the evaluation of the quality of sleep is consistent both with the subjective and the objective methods [13].

We can also see that the quality of sleep increases along with the duration of hospitalisation. Similar research conclusions were presented by Richards and Bairnsfather. The researchers showed that insomnia decreased along with the duration of hospitalisation, but patients reported morning uneasiness. This shows that regardless of how long patients stay at the hospital, the environmental changes are so strong that they are unable to replace rest in surroundings familiar to the patients [19].

Lowered quality of sleep also results from the comorbidities of ICU patients. Chronic obstructive pulmonary disease or asthma are common comorbidities and may cause the fragmentation of sleep and changes to its architecture [20]. Another clinical factor is the post-long surgery status; researchers demonstrated that during the period immediately following surgery and anaesthesia, the stage of deep sleep is shortened or absent [21]. In our study, $98.8 \%$ of subjects stayed in the ICU due to an extensive surgery requiring intensive surveillance, and they assessed the quality of their sleep as average.

The majority of patients reported an improvement in sleep directly after leaving the ICU as a result of decreased noise and the reduction of drains and catheters necessary during the therapeutic process [22]. In our study, the patients assessed their sleep after staying in the ICU, with the RCSQ, but the results did not show extreme sleep evaluations. After averaging, the majority of answers ranged between 4.39 and $4.86 \mathrm{M}$. The situation may change over time. A prospective study carried out by Parsons et al. 6 months after hospitalisation in an ICU due to acute lung injury revealed that patients presented symptoms resembling post-traumatic stress disorder and depressive syndromes. 50\% of patients reported insomnia and the worsening of mental and physical comfort [23]. 
According to the subjects, the measurement of vital signs was the factor which most disturbed sleep. This was confirmed by a 2013 study which identified blood pressure cuffs which restrict the patient's movement and give off a bad odour as one of five factors which most disturbed sleep [24]. Light was the second factor most disturbing sleep. Unfortunately, the ICU environment in question is not equipped with separate shaded patient stations. During intervention, the medical staff has to turn on the light in the entire ICU. Similar conclusions were reached by Reinstein, who additionally stressed that a considerable interference of light during a patient's night rest may disturb their circadian rhythm [25]. The collection of blood was another factor which disturbed sleep. It is worth stressing that patients hospitalised in an ICU due to an extensive surgery are not always provided with a central venous catheter. Consequently, their blood is collected by way of traditional venepuncture, which causes pain. As a standard, blood samples are collected twice a day.

Pain took the fourth place on the list of factors disturbing sleep. It was additionally demonstrated that the higher the level of pain reported on the first day of ICU hospitalisation, the stronger the position of pain as a factor affecting sleep. Jacobi et al. and Honkus found out that pain contributed to sleep disturbances in ICUs. They attributed pain to surgeries, medical interventions, and vascular lines as indispensable elements of treatment [26, 27]. In view of the difficult verbal communication with ICU patients, it is sometimes impossible to reach the desired analgesic effect [28].

Surprisingly, the patients who were administered catecholamines subjectively assessed the quality of their sleep as better. The available source literature shows a clear relationship between cardiovascular medicines and sleep disturbances. Dopamine may potentially prolong sleep stages. The same is true about epinephrine and norepinephrine, which have an impact on the REM stage marked by rapid eye movements [29].

No relationship was identified between the duration of ventilator therapy and ventilator alarms which patients reported as a sleep-disturbing factor. Every intervention of the medical staff and the patients' additional respiratory activity are related to ventilator sound alarms, which are stimuli to the patients and interrupt their sleep. In Weinhouse's study, $38.5 \%$ of patients who were mechanically ventilated for $48 \mathrm{~h}$ declared that they could not sleep. In addition, $40 \%$ of them remembered awakenings from the previous night and $30 \%$ had problems with falling asleep [30]. Aspects of mechanical ventilation most affecting sleep continuity include increased respiratory effort, abnormal gas exchange, and the absence of synchronous ventilation [1]. For this reason, patients undergoing ventilator therapy experience less effective, interrupted sleep in contrast to patients who breathe on their own. Equally important is the patient's discomfort caused by the presence of a tracheal tube or tracheostomy and the related bronchial tree toilet performed by the medical staff.

It is also worth mentioning that a 2013 study showed that as many as $70.6 \%$ of subjects related their sleep disturbances to the fact that they did not know the names of the nursing staff on duty. In addition, the patients felt uneasy, because they could not understand medical terms [22].

\section{Implications for nursing and health policy}

- Nurses' awareness of sleep-disturbing factors in the ICU setting and techniques of their prevention may significantly improve the quality of sleep that patients experience.

- Changes in sleep structure developing during an ICU stay may significantly contribute to sleep disorders once the hospitalisation is over.

\section{Conclusion}

Research results show that many factors are responsible for sleep disturbances in an ICU. A comprehensive approach to the patients in terms of their night rest is necessary. The reduction of factors disturbing sleep is a chance to obtain better sleep quality in an ICU. What remains to be done is to turn the attention of the medical staff working in an ICU to the significance of sleep and raise their awareness of the factors which may disturb sleep.

\section{Limitations}

There are a lot of obvious limitations in our study which should be mentioned when considering the methodology of future studies. The topic of sleep disorders in the ICU in Poland is literally an uncharted territory. We met with a lack of understanding on the part of personnel working on the subject of research and lack of cooperation. The patients did not fully understand the need to conduct research on sleep disorders and thus needed some assistance in filling in the questionnaire. Due to the fact that the research took place during hospitalisation, there is a risk that the responses regarding the impact of personnel on sleep disorders were not entirely objective. There was a risk that patients would not be honest, because they were afraid of worse treatment by the staff during the rest of their stay in the hospital. In our study, we focused on the assessment of quantitative factors disturbing patients' sleep in the ICU. The psychological factors such as stress, fear, or mood were not assessed and they all can influence sleep and its quality. Although the group of patients included in our study was rather homogenous-they were surgical patients-we did not explore 
their comorbidities and they can substantially affect sleep patterns and quality.

Funding The project was financed as part of statutory audits no. 549 by the Ministry of Science and Higher Education.

\section{Compliance with ethical standards}

Conflict of interest The authors declare that no conflicts of interest exist.

Ethical approval Consent to carry out the study was obtained from the Independent Bioethics Committee for Research operating by the Medical University of Gdańsk (No. NKBBN/58/2017) and from the heads of the particular departments in which the patients were hospitalised.

Open Access This article is distributed under the terms of the Creative Commons Attribution 4.0 International License (http://creativeco mmons.org/licenses/by/4.0/), which permits unrestricted use, distribution, and reproduction in any medium, provided you give appropriate credit to the original author(s) and the source, provide a link to the Creative Commons license, and indicate if changes were made.

\section{References}

1. Beltrami F, Nguyen X, Pichereau C, et al. Sleep in the intensive care unit. J Bras Pneumol. 2015;41(6):539-46.

2. Ritmala-Castren M, Virtanen I, Leivo S, et al. Sleep and nursing care activities in an intensive care unit. Nurs Health Sci. 2015;7:354-61.

3. Tembo A, Parker V, Higgins I, et al. The experience of sleep deprivation in intensive care patients: Findings from a larger hermeneutic phenomenological study. Intensive Crit Care Nurs. 2013;29:310-6.

4. Elliot R, McKinley S, Cistulli P, et al. Characterization of sleep in intensive care using 24-hour polysomnography: an observational study. Crit Care. 2013;17(2):R46.

5. Nicolas A, Aizpitarte E, Iruarrizaga A, et al. Percepcion of nighttime sleep by surgical patients in an Intensive Care Unit. Nurs Crit Care. 2008;13(1):25-33.

6. Freedman N, Kotzer N, Schwab R. Patient perception of sleep quality and etiology of sleep distruption in the intensive care unit. Am J Respir Crit Care Med. 1999;159:1155-62.

7. Simini B. Patients perceptions of intensive care. Lancet. 1999;354:571-2.

8. Nelson J, Meier D, Oei J, et al. Self-reported symptom experience of critically ill cancer patients receiving intensive care. Crit Care Med. 2001;29:277-82.

9. Granja C, Lopes A, Moreira S, et al. Patients' recollections of experiences in the intensive care unit may affect their quality of life. Crit Care. 2005;9:R96 - 109.

10. Wichniak A, Jankowski K, Skalski M, et al. Standardy leczenia zaburzeń rytmu okołodobowego snu i czuwania opracowane przez Polskie Towarzystwo Badań nad Snem i Sekcję Psychiatrii Biologicznej Polskiego Towarzystwa Psychiatrycznego. Część I. Fizjologia, metody oceny i oddziaływania terapeutyczne. Psychiatr Pol. 2017;51(5):793-814.
11. Bourne R, Minelli C, Mills G, et al. Clinical review: sleep measurement in critical care patients: research and clinical implications. Crit Care. 2007;11:226.

12. Kamdar B, Shah P, King L, et al. Patient-nurse interrater reliability and agreement of the Richards-Campbell Sleep Questionnaire. Am J Crit Care. 2012;21(4):261-9.

13. Bihari S, McEvoy D, Matheson E, et al. Factors affecting sleep quality of patients in Intensive Care Unit. J Clin Sleep Med. 2012;15(3):301-7. 8).

14. Wood A. A review of literature relating to sleep in hospital with emphasis on the sleep of the ICU patient. Intensive Crit Care Nurs. 1993;9:129-36.

15. Cooper A, Thornley K, Young G, et al. Sleep in critically ill patients requiring mechanical ventilation. Chest. 2000;117:809-18.

16. Pfeiffer E. A short portable mental status questionnaire for the assessment of organic brain deficit in elderly patients. J Am Geriatr Soc. 1975;23:433-41.

17. Richards KC, O'Sullivan PS, Phillips RL. Measurement of sleep in critically ill patients. J Nurs Meas. 2000;8(2):131-44.

18. The ordinance of the Minister of Health of 16. December 2016 on organisational standards of healthcare in the area of anaesthesiology and intensive care. Available at: http://www.dziennikustaw. gov.pl/du/2016/2218/1.pdf. Accessed 20 July 2018.

19. Richards K, Bairnsfather L. A description of night sleep patterns in the critical care unit Heart Lung 1988;17(1):35-42.

20. Kamdar B, Needham D, Collop A. Sleep deprivation in critical illness: its role in physical and psychological recovery. J Intensive Care Med. 2012;27(2):97-111.

21. Seifman M, Gomes K, Nguyen P, et al. Measurement of serum melatonin in intensive care unit patients: changes in traumatic brain injury, trauma, and medical conditions. Front Neurol. 2014;5:237.

22. Little A, Ethier C, Ayas N, et al. A patient survey of sleep quality in the intensive care unit. Minerva Anestesiol. 2012;78:406-14.

23. Parsons E, Kross E, Caldwell E, et al. Post-discharge insomnia symptoms are associated with quality of life impairment among survivors of acute lung injury. Sleep Med. 2012;13:1106-9.

24. Ehlers V, Watson H, Moleki M. Factors contributing to sleep deprivation in a multidisciplinary intensive care unit in South Africa. Curationis. 2013;36(1):E1-8.

25. Reishtein L. Sleep in mechanically ventilated patients. Crit Care Nurs Clin N Am. 2005;3:17.

26. Jacobi J, Fraser G, Coursin D, et al. Clinical practice guidelines for the sustained use of sedatives and analgesics in the critically ill adult. Crit Care Med. 2002;30:119-41.

27. Honkus V. Sleep deprivation in critical care units. J Crit Care Nurs. 2003;26:179-91.

28. Coyer M, Wheeler K, Wetzig M. Nursing care of the mechanically ventilated patient: what does the evidence say? Intensive Crit Care Nurs. 2007;23:71-80.

29. Cove-Smith J, Kirk C. CNS-related side-effects with metoprolol and atenolol. Eur J Clin Pharmacol. 1985;28:69-72.

30. Weinhouse G, Schwab R. Sleep in the critically ill patient. Sleep. 2006;29(5):707-16.

Publisher's Note Springer Nature remains neutral with regard to jurisdictional claims in published maps and institutional affiliations. 